NOTE IN REFERENCE TO A CASE

OF

\title{
MALFORMATION OF THE HEART.
}

Br T. B. PEACOCK, M.D.

Received Dec. 7th-Read Dec. 14th, 1847.

IN the report of a case of malformation of the heart, read before the Society in the last session, and published in the Transactions, I remarked that another case, from the similarity of the physical signs presented, probably of a similar description, was then under my care. Unexpected circumstances have since enabled me to test the accuracy of this opinion, and I venture to lay the result before the Society.

A female child, aged five years, was brought under my notice on the 26th of December 1846. She was stated to have been very livid at birth, but acquired a more natural colour soon afterwards, and was stout and healthy till between two and three years of age, when she began to suffer from difficulty of breathing without any assignable cause, had a slight cough, and became thinner. She had since that period been always delicate, and very susceptible to cold; and, when chilled or suffering from catarrhal affection, she became livid in the face, and had hurried and difficult breathing.

She was repeatedly seen and examined in the course of the last year. During this time the cheeks were tumid, much flushed, and with the vessels distinctly visible. The arms and hands were puffy, and the fingers and toes clubshaped at their extremities, and of a deep-red or purple colour, but not blue. The pulse was always more or less accelerated; there was some difficulty of breathing and a slight 
hacking cough. The dull space at the præcordia was somewhat greater than natural, but the chest was elsewhere fully resonant. Slight sibilant and sonorous râles were heard with the respiration; and over a large portion of the front of the chest a loud systolic murmur was audible. This murmur was thought to be most intense midway between the left nipple and sternum; but it was also very distinct from this point towards the middle of the left clavicle, across the sternum to the right side, and along the whole of the middle and lower part of the sternum. In these situations the diastolic sound was indistinct, but at the upper part of the sternum, and at the point of pulsation of the apex of the heart, the murmur was less intense and prolonged, and the diastolic sound clear. A feeble murmur was audible to the left of the spine in the interscapular region. There was no permanent turgidity or pulsation of the jugulars. The liver was large and the abdomen tumid. In September, the child returned from the sea-side, where she had been for six weeks or two months, greatly improved in general health. The murmur, however, though less intense, was still audible, and the cyanosis equally decided. Soon after this, she took scarlet fever, had severe ulceration of the throat, followed by vomiting of blood in large quantities, and died exhausted in about three weeks.

The body was examined on the 2nd of November. It was much emaciated. There were slight old adhesions at the lower and posterior part of the left lung, and some lobular condensation in both lungs. The smaller bronchial tubes contained a little secretion, but the mucous membrane was not materially reddened. The heart was of natural form. It weighed three ounces and three-quarters (avoirdupois). There was a slight deposit of fat on the surface of the right ventricle, and some old adhesions between the aorta and pulmonary artery. The right auricle was large and distended with imperfectly coagulated blood. The foramen ovale was completely closed. The right auriculo-ventricular aperture admitted a ball measuring in circumference thirty-nine French 
lines:* the valves were natural. In the cavity of the right ventricle there existed a septum, dividing the sinus from the infundibular portion; and this septum was perforated by an oval aperture twenty-one lines in circumference, by which the two divisions of the cavity communicated. The edges of the aperture were smooth, and the lining membrane and muscular structure around had undergone the fibro-cartilaginous transformation on the auricular side. The walls of the sinus of the ventricle had an average thickness of two lines; those of the infundibular portion, of only one line. The pulmonary orifice had a circumference of twenty-six and a half lines. Its valves were natural, and the ductus arteriosus was occluded. The left cavities were natural, but the auriculoventricular aperture and the orifice of the aorta were smaller than the corresponding orifices on the right side. The liver and spleen were large. Both kidneys were extensively diseased; they were large, mottled with purple patches, and very lacerable.

This case corresponded with the one formerly reported to the Society, so far as the abnormal septum was concersed, to an extent which I had by no means anticipated;-but the contraction of the pulmonary orifice, and the deficiency of the interventricular septum, which existed in the earlier case, was absent here, although, from the similarity of the physical signs, I had thought it probable they also would have been found.

Of the cases in which supernumerary septa have been found in the right ventricle (of which this is the seventh recorded example) the present one offers the least complicated deviation from the natural conformation. In this instance also (as in three of those previously related), the absence of contraction at the orifice of the pulmonary artery, or of any other cause of obstruction, to which the hypertrophied condition of the fleshy columns forming the septum can be ascribed, renders it only possible to refer the production of this septum to irregular development of the muscular parietes

[* One French line $=\cdot 08881378$ English inch.-ED. $]$ 
of the ventricle, and of the fleshy column to which the anterior fold of the tricuspid valve is attached; although this irregularity of development may have been combined with inflammation of the lining membrane occasioning adhesions between these parts.

In malformations of this description, the existence or absence of other irregularities must be regarded as indicating the period of life at which the supernumerary septa, dividing the cavity of the right ventricle, became so completely developed as to occasion obstruction to the flow of blood from the right auricle and sinus of the ventricle into the pulmonary artery. In this instance the absence of any imperfection in the auricular or ventricular septa evinces that no material amount of obstruction could have existed at the period of birth.

In one respect the present case forms a striking contrast to that formerly related. In that instance $I$ remarked upon the slight degree of cyanosis which appeared to have been present so long as no other cause of obstruction existed than the congenital contraction of the pulmonary orifice, notwithstanding the very free intermixture of the venous and arterial currents of blood, which must have taken place throughout life. The case now reported is an instance of the reverse condition; permanent cyanosis, or at least lividity of the face and extremities, having existed to a very marked degree, though the venous blood did not enter at all into the systemic vessels, and the only effect of the peculiar malformation of the heart can have been the production of constant congestion of the venous system. This case tends therefore, no less than the former, to confirm the views of Morgagni and Louis as to the cause of cyanosis. 